\title{
Overview on Adaptive Capacity to Climate Change
}

\author{
Suraj Goswami ${ }^{1}$, Vivekanand ${ }^{1}$, Pavan Kumar Harode ${ }^{1}$ and Girdhari Lal ${ }^{2}$ \\ ${ }^{1}$ ICAR-Central Soil Salinity Research Institute, Karnal, Haryana, India \\ ${ }^{2}$ JNKVV Jabalpur, M. P., India \\ *Corresponding author
}

\section{A B S T R A C T}

\begin{tabular}{l} 
K e y w o r d s \\
$\begin{array}{l}\text { Climate Change, } \\
\text { Adaptive capacity, } \\
\text { Climate, System }\end{array}$ \\
\hline Article Info \\
$\begin{array}{l}\text { Accepted: } \\
18 \text { August } 2020 \\
\text { Available Online: } \\
10 \text { September } 2020\end{array}$ \\
\hline
\end{tabular}

\section{Introduction}

Today climate change considered as one of the most concern issues because it affects the sustainable development. So, to cope with these changes, there is an introduction of a term named adaptive capacity. It can be defined as the capacity or ability of a system to adjust to the changes caused by the climate change to expand its coping capability for corresponding variability or climate change or climatic conditions of future. Adaptive capacity means the development of a strategy or designing of methods to enhance its ability towards climatic variability or changes. Adaptive capacity is a key component of IPCC (International Panel on Climate Change) definition of vulnerability. For example, the Intergovernmental Panel on Climate Change (IPCC) defines adaptive capacity as 'the ability or potential of a system to successfully respond to climate variability, and change includes adjustments in both behaviors and resources and technologies' (Adger et al., 2007).

Adaptive capacity requires information of past differently to make a strategy for upcoming future conditions of climate. It reduces the permeability of climate change towards a system. There is also a term related to adaptive capacity that is the capacity development. It can be defined as expanding the coping range strengthens the adaptive capacity of the system. Adaptive capacity is crucial to implement the systems. So many 
types of frameworks are developed at both national and state scale by different institutions.

\section{Key concept of adaptive capacity}

\section{Key component}

Information: requirement of both historical data and data from scenarios to check which kind of trend or variability is going in a particular system. Only by knowing these information we can adapt any kind of method to enhance or asses the adaptive capacity.

Resources: Developing country does not have too many resources to cope there a range of adaptive capacity. So, it is also a limiting factor, or we can say a crucial component of adaptive capacity. There are so many kinds of resources human, institutional, capital and natural. So, information about these resources will help us to that which kind of strategy should be used for a particular region.

Willingness to adapt: to adapt a strategy there should be a high will to enhance capacity development. It should reduce risk factor affected by climate change.

\section{Scale of adaption}

What kind of scale national or state, global or local. It is considering the combination of planned or reactive. We know that climatic projection plays a vital role to adopt a strategy. However, these projections should be defined in some boundary kind of space, time or information. So, we should have information about the scale of adaption.

Also know the different aspect like economic, social, geographic or environmental. After knowing the scale, we can decide the barrier (External or internal) for our strategy. For example, if at the national level availability of data is an internal barrier but if the scale of state then it becomes external (interfere with central government institutions).

\section{System and Hazards}

Capacity related to a particular system is related to a particular type of hazard. A system may be household, individual, social village, state, country or maybe we can say a globe, so every system is related to a kind of hazard. So, these hazards should be detected to enhance or increase adaptive capacity these hazards can be decided by discrete recurrent hazards, singular or unique hazards or change in the mean conditions. It is also not same for the country example India agriculture is affected by market conditions and also climate changes so to adopt a strategy depends that which factor is dominant in the respective area.

\section{Ecological system}

Climate change or variability directly or indirectly affected the ecological system. Methods to increase adaptive capacity will also a positive impact on the ecological system for example relocation of individual certain species, making of corridors between agriculture and urban land increase efficient productivity and safe environment for the species.

So adaption of methods should have consideration about the feature of the ecological system. Adaptive capacity helps non climatic stress and sustainable development.

\section{Risk framework for adaption}

Impact of climate change also depends on the risk associated with it. So vulnerability depends on how the system and is boundary get defined for example social, economic or 
say environmental. The vulnerability of a system is inversely proportional to capacity or response of the system. Risk can be indicated by the outcomes after climate change for example how many people get killed, how many get injured, how much loss of money and soon.

\section{Indicator of adaptive capacity}

It is not like that there is a list of an indicator of adaptive capacity, and we select from them that what we want. Different level and different aspect determine the different indicator of adaptive capacity for example nature of the system, what kind of significant principal hazards, elements or group that gets affected. So it depends on the policymaker that what we did and what kind of indicator he wants to choose.

\section{Guidance on enhancing adaptive capacity}

There are different components/steps of enhancing adaptive capacity are following:

Designing and scoping of and adaption project

Assessing current vulner ability

Assessing future climatic risk

Formulating an adaption strategy

Continuing adaption strategy

Note: To enhance and assessment of adaptive capacity should be affected by different factors like human, physical, capital, natural and social so they should be considered. Adaptive capacity is also get affected by the combination of socioeconomic biophysical and technology conditions.

The concept of adaptive capacity first seen in FAR (First Assessment Report) in 1990. From that to today to many types of approaches and methods has been developed regarding to this.

\section{Case studies}

Case: 1 Assessing urban adaptive capacity to climate change

There are too many studies on the vulnerability of urban on climate change. Here he studied in the metropolitan area named, Chile. Adoption of a flexible method based on the fuzzy modeling to aggregate and standardize adaptive capacity by the stepwise approach and use of seventeen indicators.

\section{The conception metropolitan area}

There are 1 million inhabitants by covering 2077 square kilometer area. The warm temperate condition was there having winter rainfall, high humidity and dry season for 4-5 months. The flood occurred in 2006 and earthquake in 2010 have severe impacts on livelihood.

\section{Developing the adaptive capacity index}

It was done in three steps. First, a collection of information related to adaptive capacity and urban vulnerability second, selection of indicator and third and last is the sensitivity correlation, and uncertainty analysis was carried out to check the strength of adaptive capacity. These steps illustrated in the given figure 1 .

Fuzzy modeling used to assess the capacity of the system by the generic adaption. It successfully tracked the how adaptive capacity changes and its determinants get changes.

\section{Case: 2 Enhancing adaptive capacity to climate change}

The case of small holder farmers in the Brazilian semi-arid region. The fourth assessment report from IPCC (International 
Panelon Climate Change) provided the characteristics analysis by the impact of climate change potential. We use the semodels and reports to enhancing the adaptive capacity of the different systems.

Fig.1 Developing stages of assessment of Adaptive capacity to address climate change

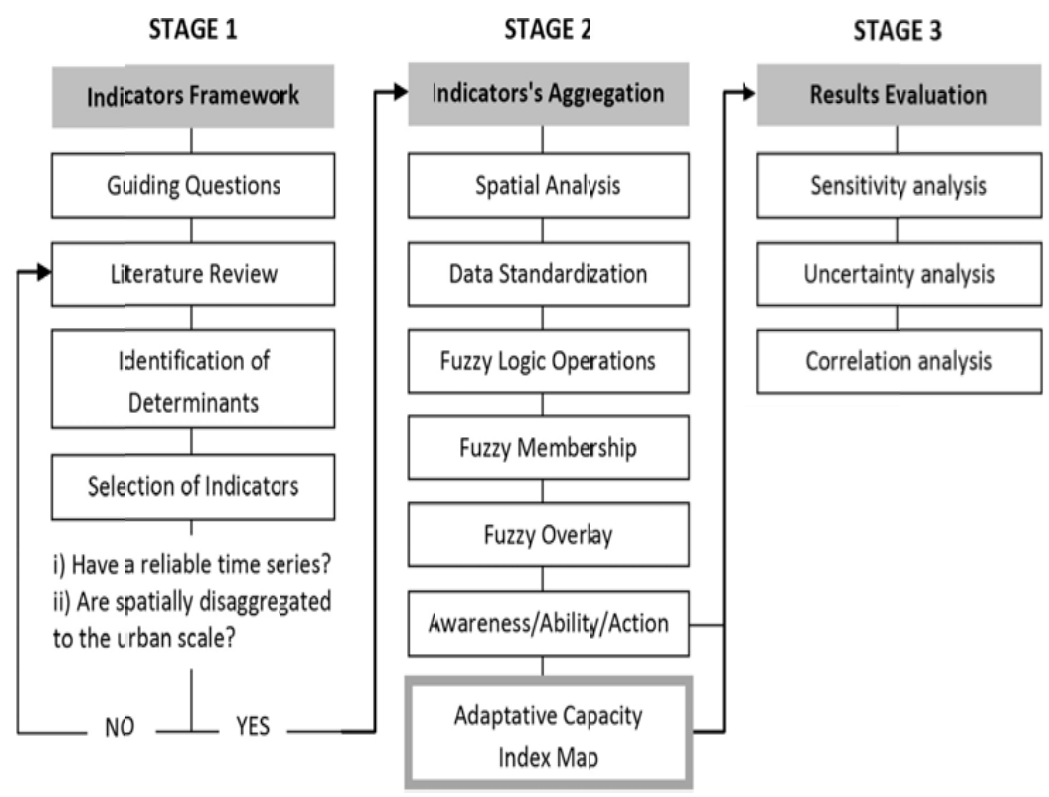

In this study, we first check out the list of climate and social vulnerabilities to the people. It is believed that poor people of developing country particularly get affected by climate change impacts due to lack of resources, capital, and knowledge to make themselves to adjust themselves to changing climatic conditions. In Brazil, the northeast region is semi-arid region and having a hydrological deficiency (maybe decrease in rainfall or increase in evaporation). It affects 2 million people of the area. Essential services available for this country are also very low for example preconditioning of rural development is missing. These conditions conclude that poverty is not only the reason behind vulnerability. Poverty is not a single barrier to enhance adaptive capacity here.

Now, authors make integration between adaption, adaptive capacity, and development. The aim of this project to develop a methodology to adapt the climate change by small holder farmer of this region. To make this integrated approach it uses APF (Adaptive Policy Frame work) steps.

Finally, this study identified three key factors which follow:

The building of awareness on current climate variability and changing the climate and future aspects.

Local community builds for technological knowledge by having an idea about adaptive capacity.

Human is excellent resources, so it focusing on female and young participators.

In conclusions from past 15 years, adaptive capacity has been rapid growth in research. Adaptive capacity is widely used to coping the ranges of the systems. Controlling and multitude factor has the adaptive capacity as an emergent property. Traditional approach is transformed into latest technical (Modeling) 
approach make it more usable. After enhancing or assessing the capacity of the system it depends that it is feasible or not. It will be continued or not or needed changes to it. However, by adopting a suitable methodology and increase in adaptive capacity increases productivity and production in more cases. Nowadays, adaptive capacity becomes the most concerned component of climate change. So before inducing any technique in a system, we should think about its adaptive capacity. By understanding the basic concept of adaptive capacity, we can develop an excellent approach to enhance and assess the adaptive capacity of the system.

\section{References}

Adger, W.N., Agrawala, S., Mirza, M.M.Q., Conde, C., O'Brien, K., Pulhin, J., Pulwarty R., Smit B., Takahashi, K., 2007. Assessment of adaptation practices, options, constraints and capacity. Cambridge University Press, Cambridge, UK, Pp. 717-743.

Munoz, D., A., Metzger, M., J., Strut, N., Wlison, A.M.W., 2016. Assessing urban capacity to climate change. Journal of Environmental Management,
$183,314-324$.

Simoes, A.F., Klingerman, D.C., Rovere, E.L.L., Maroun, M.R., Barata, M., Obermaier, M., 2010. Enhancing adaptive capacity to climate change: The case of smallholder farmers in the Brazilian semi-arid region. Environmental science and policy 13,801-808.

Bernthal, F., Dowdeswell, E., Luo, J., Attard, D., Vellinga, P., Karimanzira, R. IPCC 1990. Climate change - The IPCC Response Strategies, contribution of working group III to the First Assessment Report of the Intergovernmental Panel on Climate Change.

Hoang, L., 2011. Adaptive capacity Framing the concept and building a framework for assessment of adaptive capacity to climate change in the water sector 'Master thesis Integrated Water Management ESS-80836 Chair group: Earth System Science - Climate Change Study program: Master Environmental Sciences under guidance of Prof. Dr. Wim Cofino \& Dr. FulcoLudwig

Brooks, N., Adger, W.N., Assessing and enhancing adaptive capacity.

\section{How to cite this article:}

Suraj Goswami, Vivekanand, Pavan Kumar Harode and Girdhari Lal. 2020. Overview on Adaptive Capacity to Climate Change. Int.J.Curr.Microbiol.App.Sci. 9(09): 2519-2523.

doi: https://doi.org/10.20546/ijcmas.2020.909.315 